Association for Information Systems

AIS Electronic Library (AISeL)

Wirtschaftsinformatik 2021 Proceedings

Track 20: Management of digital processes \& architectures

\title{
Supporting the Development and Implementation of a Digitalization Strategy in SMEs through a Lightweight Architecture-based Method
}

Nils Johann Tschoppe

Leuphana Universität Lüneburg

Paul Drews

Leuphana Universität Lüneburg

Follow this and additional works at: https://aisel.aisnet.org/wi2021

Tschoppe, Nils Johann and Drews, Paul, "Supporting the Development and Implementation of a Digitalization Strategy in SMEs through a Lightweight Architecture-based Method" (2021).

Wirtschaftsinformatik 2021 Proceedings. 5.

https://aisel.aisnet.org/wi2021/EManagementofdigitalprocesses20/Track20/5

This material is brought to you by the Wirtschaftsinformatik at AIS Electronic Library (AISeL). It has been accepted for inclusion in Wirtschaftsinformatik 2021 Proceedings by an authorized administrator of AIS Electronic Library (AISeL). For more information, please contact elibrary@aisnet.org. 


\title{
Supporting the Development and Implementation of a Digitalization Strategy in SMEs through a Lightweight Architecture-based Method
}

\author{
Nils J. Tschoppe ${ }^{1}$, Paul Drews ${ }^{1}$ \\ ${ }^{1}$ Leuphana University of Lüneburg, Institute of Information Systems, Lüneburg, Germany \\ \{nils.tschoppe,paul.drews\}@leuphana.de
}

\begin{abstract}
Like larger companies, small and medium-sized enterprises (SMEs) need to develop and implement a digitalization strategy. However, they face specific challenges such as a lack of IT know-how, relevant market information and appropriate methods for developing a strategy. Following the Action Design Research method and in cooperation with two medium sized companies, we started to develop a lightweight, architecture-based method for the development and implementation of digitalization strategies in SMEs.
\end{abstract}

Keywords: Digital Entrepreneurship, Enterprise Architecture Management, Small and medium-sized enterprises, Digitalization Strategy, Digital Transformation

\section{$1 \quad$ Introduction}

The digital transformation as a technology-based change process is not limited to large and established companies. In times of a digital economy, enterprises of all sizes and ages need to rethink their strategy, organization and technology use. This has been referred to as digital entrepreneurship in the literature and it results in manifold change and innovation activities [1-4]. However, most research in this field is based on the assumption that a professional and sufficiently large IT organization with differentiated roles is established in the organization $[5,6]$. SMEs, especially away from the conurbations, often face special challenges such as high exploration costs, perceived unbalance of risks and chances for the adoption of innovations and technologies, a lack of relevant market information as well as insufficient digital skills of employees [610]. With increasing relevance in practice and research [11, p. 5], the management of enterprise architecture (EA) is considered to be an "essential enabler of the digital transformation" [12, p. 280]. With an enterprise-wide view on organizational and technological artifacts, it supports the alignment of business and IT $[11,13]$. It helps to document and analyze the current state and serves as the basis for planning future target states and transformation steps [13-19]. Digital transformation processes may lead to tensions on multiple organizational levels [3]. To anticipate and address these tensions, experts from different departments and levels should be involved in the development process while considering the 'big picture' consisting of strategic objectives, business 
processes, and IT landscape [20]. In contrast to existing complex frameworks such as TOGAF [21] and FEAF v2 [22], we seek to develop a more lightweight, visualizationoriented and pragmatic approach for SMEs and realize Winter's idea of architectural thinking for this field [23].

Hence, our research question is: How can SMEs develop and implement digitalization strategies using a lightweight, architecture-based method?

\section{Research Approach}

While this work in progress seeks to contribute to the information systems research discipline by advancing methods of enterprise architecture modelling and management, it also draws upon and contributes to the literature on digital entrepreneurship. In order to develop and evaluate a solution that is both, theory-ingrained and practice-oriented, we employed the Action Design Research (ADR) method according to Sein et al. [24], which focuses on building, intervening and evaluating (BIE) artifacts and allows to codevelop an approach in practice while also supporting the generalization and theorizing.

During the preparation phase, two companies - an online-agency (A) with approximately 100 employees which can be classified as a digital "gazelle" [25] as well as the headquarter of a more senior company (B) selling luxury outdoor furniture with approximately 200 employees - were identified as particularly suitable for the development of a digitalization strategy. The extraordinary growth despite regional restrictions of company A and the advanced maturity, expansion efforts and corporate integration of company B serve as an interesting contrast.

In the problem formulation stage, we diagnosed the lack of an explicit digitalization strategy in both companies. As digitalization describes "the manifold sociotechnical phenomena and processes of adopting and using technologies in broader individual, organizational, and societal contexts" [26, p. 302], a digitalization strategy follows the overall corporate strategy and goes far beyond the mere technology trend; "it constitutes a holistic intention of a company to streamline all activities regarding the digital transformation process to generate competitive advantages through new technologies and methods" [27, p. 670]. With special emphasis on the redesign of the software landscape (A) and the use of new technologies such as virtual and augmented reality (B), the selected BIE form was organization-dominant in both cases as we seek to create a method for developing a digitalization strategy. In the alpha cycle, we iterated and evaluated early designs of the digitalization strategy in workshops with the CEO and the $\mathrm{COO}$ (A) and the Head of IT (B). As part of a first as-is analysis, the application of Porter's five competitive forces that determine industry profitability [28, p. 5], amongst others, helped us to develop an understanding of the business ecosystem [29], enterprise systems used therein as well as to reveal potential dependencies. It was accompanied by an analysis of archival material such as industry reports, process descriptions, the organizational chart and a transcript of vision and values as part of the business strategy and supplemented by instruments such as the Gartner Hype Cycle to identify relevant technologies. For identifying inefficiencies and outdated, incompatible software, we mapped existing software to an organization-specific model of Porter's generic value 
chain [28, p. 37]. This helped us to review the core processes and served as the starting point for discussing which software will be necessary in the future (to-be landscape). In the beta cycle, we took our preliminary findings into a wider organizational setting as our know-how was limited in terms of strategy (B) and software selection (A). By inviting the CEO, the Sales Manager and other experts from the business departments, we were able to enrich our findings in a workshop (B). As Company B's business was more affected by Covid-19, the data collection had to be stopped in March 2020. Nevertheless, we complemented our data by conducting semi-structured interviews (one offline and seven online) on the different levels at company A including the two CEOs \& founders, the COO, four department managers as well as a trainee. These interviews lasted between 20 and 90 minutes depending on experience and responsibility of the interviewee and covered questions ranging from the individual software usage and acceptance to personnel and strategic issues such as digital literacy and the market environment. By analyzing and coding these with MAXQDA [30], we were able to further refine our lightweight, architecture-based method as well as our understanding of the internal structure and external factors. In addition, we conducted a subsequent online workshop across the departments which were likely to be most affected by the transformation to identify internal capabilities and prepare the development of the digitalization strategy and roadmap. To validate and enrich our findings theoretically and practically, intermediate findings regarding the development of the digitalization strategy were mirrored several times with the $\mathrm{COO}$ (A) and the Head of IT (B) while reviewing the lightweight, architecture-based method through interdisciplinary discussions in a circle of researchers from different fields such as information systems, strategic management, psychology and organizational science.

\section{$3 \quad$ Results}

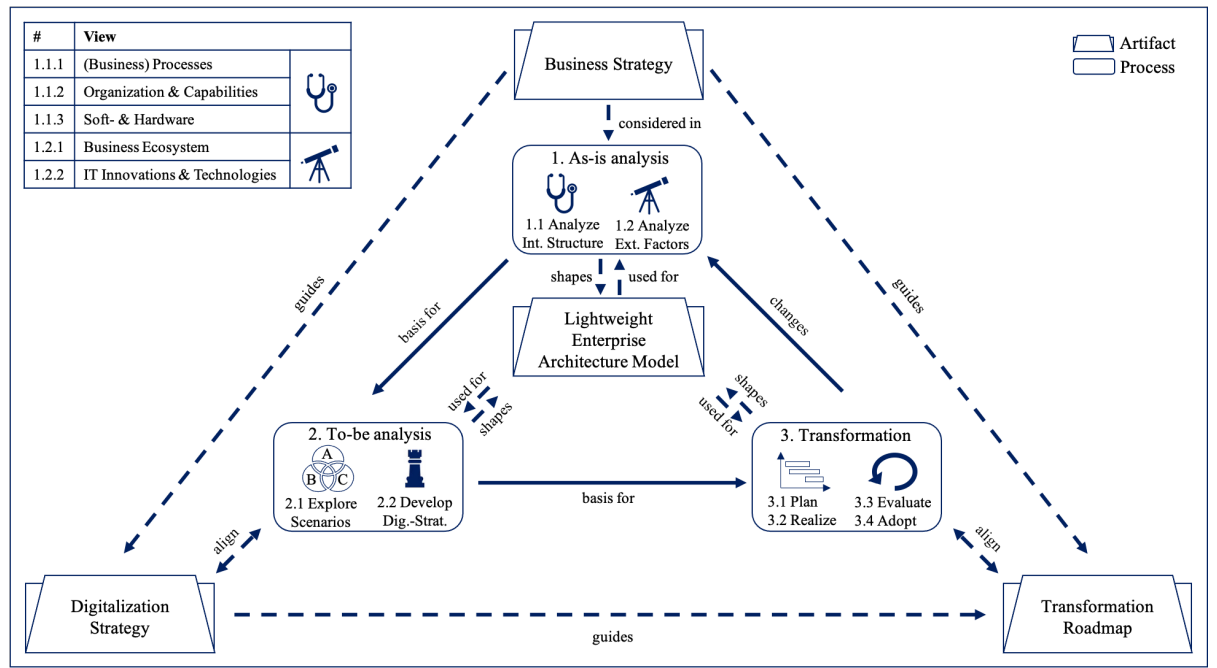

Figure 1. Lightweight, architecture-based Digitalization Strategy Development Method 
Based on the findings of the two companies investigated so far, we propose our method for the development of a digitalization strategy in SMEs and its transformation with special attention to a lightweight visualization of the enterprise architecture (Figure 1).

First of all, an as-is analysis of the internal structure and external factors is beneficial to gain a deeper understanding of the need for necessary changes. Taking into account the business strategy helps to prevent shortsightedness in the development process as it can have a decisive influence on the later design of the digitalization strategy and may additionally provide useful business information. The analysis of the organization and its capabilities as well as the (business) processes linked to the existing software and hardware landscape (1.1) enables a better understanding of potential dependencies in order to reduce medium to long-term costs caused by inefficiencies and wrong IT investments. By doing so, it may be also important to point out interrelations with supplier portals and their interfaces when it comes to selecting, developing or implementing new software. Documents such as organization and capability charts, hardware and software constellations and process descriptions, which may be supplemented by a Business Model Canvas [31] or a Value Proposition Canvas [32], can help to gain a comprehensive picture of the internal structure. As an illustration, it can be advantageous to map the company's software solutions and their dependencies to primary and secondary activities in Porter's generic value chain [28, p. 37] tailored to the enterprise. The significance of required changes can be pictured, for example, as simple traffic lights (e.g. urgent need for change, needs to be checked, meets requirements). In the case of a multi-divisional organization with several departments, it can also be helpful to represent these as swim lanes and to map existing software to their activities, e.g. ranging from sales generation to invoicing and maintenance. The external view (1.2) comprises the identification of relevant technologies and IT innovations as well as factors of the business ecosystem, which can have a direct (e.g. interlocked supplier processes) or indirect (e.g. competition, customer, partner) impact on the company. One effective tool for this is Porter's five competitive forces that determine industry profitability [28, p. 5] which allows a comprehensive visualization of the market environment and may be supplemented by industry-reports and instruments such as the Gartner Hype Cycle. This perspective can also provide interesting information about which technologies and software the competitors use. After an initial draft of the internal structure and external factors has been prepared by the person or team responsible for the digitalization strategy, further employees from the departments to be transformed should be involved to enrich these findings. This may also help to sensitize employees to technical and organizational changes within the transformation (3).

Secondly, it has proven promising to explore several to-be scenarios of the internal structure under consideration of external factors (2.1) based on the findings of the as-is analysis. This supports prioritization and again sensitizes for the transformation process. After creating a comprehensive overview of the current state and developing a potentially promising scenario, the next step is to develop the business aligned digitalization strategy (2.2). Here, an illustrative presentation of the data compiled in phase 1 and 2.1 should form the basis, coordinated with other stakeholders within the company. 
To operationalize the digitalization strategy, a transformation roadmap tailored to the company and its capabilities has to be developed closely coordinated with existing and planned company-wide projects (3.1). For this, it is necessary to allocate resources as well as to determine who is responsible for the realization of the (sub-)projects underlying the transformation (3.2). In some cases, especially when dealing with new technologies or complex software, it can be necessary to draw on external know-how. If this is the case, a selection of possible partners must be made and their advantages and disadvantages in terms of costs, expertise and capacities weighed up. In any case, the transformation process has to be evaluated (3.3) and adjusted (3.4) regularly as changes in 1.1 and 1.2 may occur.

However, we also observed some frictions in this model between theoretical modeling and practical applicability. Despite the lack of an elaborated business strategy (A and B) and without an existing IT department (A), it was nevertheless possible to build on the knowledge of the IT responsible person(s). In smaller companies, such a person with knowledge about the technical properties of IT systems might not be available. While the business strategy is usually anchored in the heads of the management, it is rarely written down and communicated, which may hinder the development of the digitalization strategy and the transformation as it may reveal important insights, e.g. of the business ecosystem, internal processes and technology trends.

\section{Conclusion and Outlook}

In this paper, we present our research approach and intermediate findings towards the development of a lightweight, architecture-based method for developing and implementing digitalization strategies in SMEs. The method proposes to create coordinated, comprehensive visualizations of relevant views including internal processes and external influences. A structured collection of data and the uncovering of dependencies between IT and business through the enterprise architecture lens helps to set priorities when developing a digitalization strategy while supporting transparency and documentation [13]. The underlying transformation process, however, does not necessarily imply the use of new technologies such as virtual or augmented reality (B), but often also requires basic work like redesigning the software and hardware landscape (A). Besides this, there are manifold reasons why digital transformation projects fail. One of the main reasons is the disconnection between the pure formulation of a strategy and its implementation [33] which has to be addressed through a constant questioning of the status quo. In order to validate and generalize our results, it is necessary to investigate further companies from different industries. We will take a closer look at the phases and evaluate the results at A and B after some time. So far, the consideration of digital technologies has played a subordinate role in entrepreneurial research and its intersection with information systems related research [4, 34, 35]. The investigation of the specific conditions as well as success factors including the selection, evaluation and appropriation of IT innovations in the context of developing a digitalization strategy is still in its infancy and therefore offers a promising field of research. 


\section{References}

1. Böhmann, T., Drews, P., Meyer-Blankart, C.: Digitale Exzellenz. Eine Bestandsaufnahme zur Digitalisierung deutscher Unternehmen und Behörden. Sopra Steria (2015)

2. Hinings, B., Gegenhuber, T., Greenwood, R.: Digital innovation and transformation: An institutional perspective. Inf. Organ. 28, 52-61 (2018)

3. Nambisan, S., Wright, M., Feldman, M.: The digital transformation of innovation and entrepreneurship: Progress, challenges and key themes. Res. Policy. 48, 1-9 (2019)

4. Nambisan, S.: Digital Entrepreneurship: Toward a Digital Technology Perspective of Entrepreneurship. Entrep. Theory Pract. 41, 1029-1055 (2017)

5. Horlach, B., Drews, P., Schirmer, I.: Bimodal IT: Business-IT alignment in the age of digital transformation. In: Multikonferenz Wirtschaftsinformatik. pp. 1417-1428. MKWI, Ilmenau (2016)

6. Passerini, K., Tarabishy, A. El, Patten, K.: Information Technology for Small Business. Springer Dordrecht, Heidelberg, London, New York (2012)

7. Huck-Fries, V., Wiesche, M., Pfluegler, C., Krcmar, H.: The hateful six Factors hindering Adoption of innovation at small and medium sized enterprises. In: 22nd Americas Conference on Information Systems. AMCIS, San Diego (2016)

8. Abel-Koch, J., Obaidi, L. Al, Kasmi, S. El, Acevedo, M.F., Morin, L., Topczewska, A.: Going Digital The Challenges Facing European SMEs. KfW (2019)

9. Huck-Fries, V., Pflügler, C., Wiesche, M., Krcmar, H.: Innovationshemmnisse für kleine und mittlere Unternehmen. In: Management digitaler Plattformen, Informationsmanagement und digitale Transformation. pp. 297-312. Springer Fachmedien GmbH, Wiesbaden (2018)

10. Zimmermann, V., Thomä, J.: Innovationshemmnisse in KMU - vielfältige Hemmnisse sprechen für eine breit aufgestellte Förderpolitik. KfW (2016)

11. Simon, D., Fischbach, K., Schoder, D.: An Exploration of Enterprise Architecture Research. In: Communications of the Association for Information Systems. pp. 1-72. AIS (2013)

12. Hanschke, I.: Digitalisierung und Industrie 4.0 - einfach und effektiv: systematisch und lean die digitale Transformation meistern. Carl Hanser Verlag, München (2018)

13. Aier, S., Winter, R.: Unternehmensarchitektur - Literaturüberblick und Stand der Praxis. Wirtschaftsinformatik. 50, 292-304 (2008)

14. Winter, R., Fischer, R.: Essential layers, artifacts, and dependencies of enterprise architecture. In: 10th IEEE International Enterprise Distributed Object Computing Conference Workshops. IEEE, Hong Kong (2006)

15. Buckl, S.M.: Developing organization-specific enterprise architecture management functions using a method base. Technische Universität München (2011) 
16. Petrikina, J., Drews, P., Schirmer, I., Zimmermann, K.: Integrating business models and enterprise architecture. In: 18th International Enterprise Distributed Object Computing Conference Workshops and Demonstrations. pp. 47-56. IEEE, Ulm (2014)

17. Schmidt, J., Drews, P.: Entwicklung und Evaluation eines Metamodells zur Verbesserung der unternehmensweiten Entscheidungsorientierung mithilfe der Unternehmensarchitektur. In: 12th International Conference on Wirtschaftsinformatik. pp. 1814-1828. AIS, Osnabrück (2015)

18. Aier, S., Ahrens, M., Stutz, M., Bub, U.: Deriving SOA evaluation metrics in an enterprise architecture context. In: Di Nitto, E. and Ripeanu, M. (eds.) Service-Oriented Computing - ICSOC 2007 Workshops. LCNS, vol 4907. pp. 224-233. Springer, Berlin, Heidelberg (2009)

19. Keuntje, J.H., Barkow, R., Mannmeusel, T.: Enterprise Architecture Management in der Praxis. Symposion Publishing, Düsseldorf (2010)

20. Horlach, B., Drechsler, A., Schirmer, I., Drews, P.: Everyone's Going to be an Architect: Design Principles for Architectural Thinking in Agile Organizations. In: 53rd Hawaii International Conference on System Sciences. HICSS, Hawaii (2020)

21. The Open Group: The Open Group Architecture Framework TOGAF. van Haren Publishing, Zaltbommel (2007)

22. Federal government of the United States: Federal Enterprise Architecture Framework Version 2, https://obamawhitehouse.archives.gov/sites/default/ files/omb/assets/egov_docs/fea_v2.pdf, last accessed 2020/08/23

23. Winter, R.: Architectural Thinking. Wirtschaftsinformatik. 56, 395-398 (2014)

24. Sein, M.K., Henfridsson, O., Purao, S., Rossi, M., Lindgren, R.: Action Design Research. MIS Q. 35, 37-56 (2011)

25. Birch, D.G.W.: Job Creation in America - How Our Smallest Companies Put the Most People to Work. Univ. Illinois Urbana-Champaign's Acad. Entrep. Leadersh. 27, 1204-1206 (1987)

26. Legner, C., Eymann, T., Hess, T., Matt, C., Böhmann, T., Drews, P., Mädche, A., Urbach, N., Ahlemann, F.: Digitalization: Opportunity and Challenge for the Business and Information Systems Engineering Community. Bus. Inf. Syst. Eng. 59, 301-308 (2017)

27. Pfenning, P., Eigner, M.: A Novel Procedure Model for Developing Individualized Digitalization Strategies. Proc. Des. Soc. Des. Conf. 1, 667-676 (2020)

28. Porter, M.E.: Competitive Advantage - Creating and Sustaining Superior Performance. The Free Press, New York (1985)

29. Moore, J.F.: Business Ecosystems and the View from the Firm. Antitrust Bull. 51, 31-75 (2006)

30. VERBI Software: MAXQDA 2020. VERBI Software, Berlin (2019)

31. Osterwalder, A., Pigneur, Y.: Business Model Generation: A Handbook for Visionaries, Game Changers, and Challengers. Wiley, New York (2010)

32. Osterwalder, A., Pigneur, Y., Bernarda, G., Smith, A.: Value Proposition Design: How to Create Products and Services Customers Want. Wiley, New 
York (2014)

33. Correani, A., Italia, M., Massis, A. De, Frattini, F., Petruzzelli, A.M., Natalicchio, A.: Implementing a Digital Strategy: Learning from the Experience of Three Digital Transformation Projects. Calif. Manage. Rev. In press (2020)

34. Recker, J., von Briel, F.: The Future of Digital Entrepreneurship Research: Existing and Emerging Opportunities. In: 40th International Conference on Information Systems. pp. 1-9. ICIS, München (2019)

35. Nambisan, S., Siegel, D., Kenney, M.: On open innovation, platforms, and entrepreneurship. Strateg. Entrep. J. 12, 354-368 (2018) 